\title{
DESPROTEGER LO PROTEGIDO, ESTRATAGEMAS PARA SUSTRAER Y/O PERMITIR EL DECRECIMIENTO DE LAS ÁREAS PROTEGIDAS, ESTUDIO DE CASO EN EL AMAZONAS BRASILERO
}

\author{
DESPROTEGER O PROTEGIDO, ESTRATÉGIAS PARA SUBTRAIR E/OU \\ PERMITIR A DIMINUIÇÃO DAS ÁREAS PROTEGIDAS, ESTUDO DE CASO NA \\ AMAZÔNIA BRASILEIRA
}

\section{UNPROTECTION OF THE PROTECTED, STRATEGIES FOR SUBTRACTING AND / OR ALLOWING THE REDUCTION OF PROTECTED AREAS, CASE STUDY IN BRAZILIAN AMAZON}

\author{
Diana Magally Correa Valero \\ https://orcid.org/0000-0002-5894-5213 / diana.correa@ucaldas.edu.co \\ Universidad de Caldas. \\ Caldas, Colômbia.
}

\begin{abstract}
RESUMEN
En general, conocemos que el Amazonas está siendo incendiado y que mueren miles de especies durante el proceso, sabemos que sucede en toda América Latina, y sabemos que los gobiernos hacen poco por detener esta deforestación. Lo que ignoramos, es que existen Políticas de Gobierno, que cohonestan dicha deforestación con discursos "incendiarios"; para discutir esta situación, realizaremos un análisis de este discurso en el actual gobierno de Jair Bolsonaro; quien, a través de medios oficiales tales como NY Times, BBC, O Globo, entre otros, ha reconocido la autonomía brasilera en sus decisiones sobre el "pulmón del mundo": El Amazonas. La discusión del párrafo anterior, entre la soberanía nacional versus patrimonio común de la humanidad, no es nueva, se encuentra en los convenios internacionales de diversidad biológica, cambio climático, protección de bosques, y lucha contra la desertificación, firmados en Rio de Janeiro en 1992. En esta investigación verificaremos como, la mezcla de enmiendas constitucionales aprobadas en el Congreso de Brasil en los últimos tres años, específicamente en los gobiernos de Temer y Bolsonaro, mezcladas con un discurso político presidencial sostenido en este tiempo, han permitido que: mineros, agricultores, ganaderos y empresarios privados, hayan incendiado el Amazonas, esperando a ver qué pasa... Para realizar un análisis de discurso partiremos de una perspectiva histórica, verificando las políticas de gobierno frente al Amazonas en los últimos periodos presidenciales, (Lula, Rousseff, Temer, Bolsonaro) para concluir que, aunque conforme con los datos científicos existentes en las ONG's internacionales, se había avanzado en la conservación de la selva amazónica; sin embargo, hoy el Amazonas se encuentra en llamas. ¿Cuáles son las decisiones jurídico políticas, e incluso, las enmiendas constitucionales que se han realizado en los últimos años, para permitir el aprovechamiento económico del amazonas brasilero? ¿De qué manera el discurso de gobierno del presidente Bolsonaro se relaciona con la deforestación del Amazonas? ¿Cuál es el aporte que los científicos están realizando hoy, en el campo político para la defensa del Amazonas brasilero? Son las respuestas que encontraremos a continuación.
\end{abstract}

Palabras clave: Amazonas; Áreas protegías; Políticas publicas; Políticas de Gobierno; Enmienda constitucional.

\section{ABSTRACT}

In general terms, we know that the Amazon is being burned and that thousands of species have died during the process. We know that this is happening throughout Latin America, and we know that governments do very little to stop this deforestation. What we ignore is that there are Government Policies which cover up such deforestation with "incendiary" speeches. A discourse analysis on the current government of Jair Bolsonaro who, through official media such as NY Times, BBC, and O Globo among others, has recognized Brazilian autonomy in its decisions on the "lung of the world", the Amazon, will be conducted to discuss this situation. The discussion of the previous paragraph between national sovereignty and the world heritage site is not new. It is found in the international agreements of biological diversity, climate change, forest protection, and the fight against desertification signed in Rio de Janeiro in 1992. This research will allow verifying how the combination of constitutional amendments approved in the Congress of Brazil in the last 
DESPROTEGER LO PROTEGIDO, ESTRATAGEMAS PARA SUSTRAER Y/O PERMITIR EL DECRECIMIENTO DE LAS AREAS PROTEGIDAS, ESTUDIO DE CASO EN EL AMAZONAS BRASILERO

three years, specifically during the governments of Temer and Bolsonaro, mixed with a presidential political discourse held during these years, have allowed miners, farmers, cattle breeders and private entrepreneurs to burn the Amazon, waiting to see what happens ... To carry out the discourse analysis, we will start from a historical perspective, verifying government policies regarding the Amazon in the last presidential periods (Lula, Rousseff, Temer, Bolsonaro) to conclude that, although in accordance with the scientific data existing in the international NGOs, progress has been made in the conservation of the Amazon rainforest. However, the Amazon is on fire today. What are the political legal decisions, and even the constitutional amendments that have been made in recent years to allow the economic use of the Brazilian Amazon? How does President Bolsonaro's government speech relate to the deforestation of the Amazon? What is the contribution that scientists are making today in the political field for the defense of the Brazilian Amazon? The answers to these questions will be found in this text.

Keywords: The Amazon; Protected areas; Public policies; Government policies; Constitutional amendment.

\section{RESUMO}

Em geral, sabemos que a Amazônia está sendo queimada e que milhares de espécies morrem durante o processo, sabemos que isso acontece em toda a América Latina e sabemos que os governos fazem pouco para impedir esse desmatamento. $\mathrm{O}$ que ignoramos é que existem políticas do governo que corroboram esse desmatamento com discursos "incendiários"; Para discutir essa situação, faremos uma análise desse discurso no atual governo de Jair Bolsonaro; quem, através da mídia oficial como o NY Times, BBC, O Globo, entre outros, reconheceu a autonomia brasileira em suas decisões sobre o "pulmão do mundo": a Amazônia. A discussão do parágrafo anterior, entre soberania nacional versus patrimônio comum da humanidade, não é nova, encontra-se nas convenções internacionais de diversidade biológica, mudança climática, proteção florestal e combate à desertificação, assinada no Rio de Janeiro em 1992. Nesta investigação, verificaremos como, a mistura de emendas constitucionais aprovadas no Congresso do Brasil nos últimos três anos, especificamente nos governos de Temer e Bolsonaro, misturada com um discurso político presidencial realizado na época, permitiu: mineiros, agricultores , agricultores e empresários privados, queimaram a Amazônia, esperando para ver o que acontece ... Para realizar uma análise do discurso, partimos de uma perspectiva histórica, verificando as políticas governamentais contra a Amazônia nos últimos períodos presidenciais (Lula, Dilma, Temer, Bolsonaro) para concluir que, embora de acordo com os dados científicos existentes nas ONGs. $s$ internacional, houve progresso na conservação da floresta amazônica; No entanto, hoje a Amazônia está pegando fogo. Quais são as decisões políticas legais, e até as emendas constitucionais que foram feitas nos últimos anos, para permitir o uso econômico da Amazônia brasileira? Como o discurso do governo Bolsonaro se relaciona com o desmatamento da Amazônia? Qual a contribuição dos cientistas hoje, no campo político de defesa da Amazônia brasileira? São as respostas que encontraremos a seguir.

Palavras-chave: Amazônia; Áreas protegidas; Políticas públicas; Políticas de governo; Emenda constitucional.

\section{SUMÁRIO}

INTRODUCCIÓN. 1 EL SISTEMA DE ÁREAS PROTEGIDAS, COMO UNA ESTRATEGIA DE CONSERVACIÓN DEL ESTADO; 2 LAS ÁREAS PROTEGIDAS, SEGÚN LA LEY 9.985 DE 2000, DEL EX PRESIDENTE LULA DA SILVA; 3 CREACIÓN DEL SISTEMA NACIONAL DE UNIDADES DE CONSERVACIÓN EN BRASIL; 4 EL SISTEMA NACIONAL DE UNIDADES DE CONSERVACIÓN DE LA NATURALEZA (SNUC); 5 TIERRAS INDÍGENAS Y CONSERVACIÓN DE LA BIODIVERSIDAD EN EL BRASIL; 6 CUANDO LA CIENCIA Y LA POLÍTICA NO ENCUENTRAN EN UN LUGAR COMÚN (DESENCONTRO); 7 CAMBIO CLIMÁTICO; 8 AMAZONIA Y CAMBIO CLIMÁTICO; 9 LA SELVA AMAZONICA, EL PULMÓN DEL MUNDO; 10 LA AMAZONIA ES NUESTRA, NO SUYA!; 11 ENMIENDAS CONSTITUCIONALES, QUE AFECTAN LA PARTICIPACIÓN SOCIAL EN LA CONSERVACIÓN DEL AMAZONAS BRASILERO; 12 EL GASTO PÚBLICO SOCIAL; CONCLUSIÓN. REFERENCIAS

\section{INTRODUCCIÓN}

El encuentro de las aguas entre el rio Solimoes y el rio Amazonas, es una mezcla de tintes azules y castaños... los botos o delfines rosados y grises saltan... intentando agarrar algún pez, que intenta huir de las redes de los pescadores; pescadores y "golfinhos" trabajan juntos en el encuentro de las aguas. 
Algunos pescadores de Santarem, también lo denominan "desencontro" o "briga das aguas" es decir, un desencuentro o pelea de las aguas.

En el estudio de caso que nos ocupa, analizaremos como, a pesar de existir los datos científicos necesarios para detener de inmediato la deforestación de la Amazonia, esta es cohonestada por el discurso del gobierno de Jair Bolsonaro, además analizaremos dos enmiendas constitucionales: la primera, congelar el gasto público social por 20 años en el gobierno de Michel Temer, y la segunda, consultar las asambleas antes de crear un área protegida estatal, en el caso Roraima, estas dos enmiendas, impiden el desarrollo de "una política de participación social en la conservación de las áreas protegidas”, como el objetivo principal de analisis de esta investigación.

Frente a los datos científicos, el actual presidente de la república de Brasil, se ha manifestado desprestigiándolos, negándolos, o incluso burlándose de estos; pero además ha insistido en no tener tierras improductivas en Brasil, y en justificar públicamente que la Amazonia es de los Brasileros y no un patrimonio común de la humanidad. Analizaremos entonces como los datos científicos no son tenidos en cuenta para la conservación del pulmón del mundo, la Amazonia.

Este es un artículo original, resultado de la investigación intitulada “Análisis de la política de participación social en la conservación, estudio de caso comparado Brasil - Colombia", financiado por la Universidad de Caldas.

Mediante la aplicación del método empírico analítico, y el método inductivo, partiremos del análisis de documentos y entrevistas oficiales, sobre las áreas protegidas de los últimos cuatro presidentes brasileros, posteriormente analizaremos el actual discurso político del presidente del Brasil sobre el Amazonas, y lo contrastaremos con las enmiendas constitucionales, que se relacionan con la participación social en la conservación, frente a los datos científicos sobre el estado del Amazonas brasilero.

Brasil, es considerado como el país con mayor diversidad a nivel mundial, posee diferentes ecosistemas tales como "Amazonia, cerrado y mata atlántica" entre otros, estas características exigen compromiso y capacidad de respuesta ante los tratados internacionales de conservación ambiental firmados por Brasil, como lo son el Convenio de Biodiversidad, el Convenio de Cambio Climático, el Convenio contra la Desertificación, entre otros importantes instrumentos internacionales, que pretenden preservar a la especie humana, la flora y la fauna, la diversidad genética y ecosistémica sobre la faz tierra.

Los acuerdos internacionales para la preservación ambiental, crean obligaciones concretas para los países firmantes: delimitación de las áreas protegidas, de los humedales, de los bienes 
de patrimonio natural y cultural, etc. y la aplicación de instrumentos de medición sobre el incremento o disminución de los gases de efecto invernadero; en contraparte, el apoyo a nivel internacional, propenderá por la creación de fondos internacionales para la preservación de las áreas protegidas, los humedales, el patrimonio natural y cultural, y el reconocimiento de los aportes de Brasil en la lucha contra el cambio climático.

Sin embargo, esta lucha por la conservación de la biodiversidad y en especial de las áreas protegidas, también ha sido cuestionada. Importantes teóricos contemporáneos han denunciado la relación existente entre el poder y la manera en que se designan las cosas (FOUCAULT, 1968) invitándonos a "intentar hacer que lo obvio se convierta en problemático." (ESCOBAR, 1999) para desentrañar esa relación, se analizara el concepto de conservación, teniendo en cuenta que "Las conceptualizaciones actuales no son inocentes; se construyen a partir de experiencias históricas y culturales que se esconden en su seno." (ESCOBAR, 1996) Esta corriente critica también ha puesto en discusión la designación económica que se otorga a los "recursos naturales" en contraposición a la naturaleza humanizada de algunas comunidades locales, y a la distribución equitativa de los beneficios obtenidos por "la utilización de los conocimientos, innovaciones y prácticas para la conservación de la diversidad biológica por parte de las comunidades indígenas." (ILSA, 1999)

Según la ONU, Brasil es uno de los líderes de la lista de 18 países megadiversos del mundo. Alberga entre $15 \%$ y $20 \%$ de la diversidad biológica del mundo, con 120.000 especies de invertebrados, unos 9.000 vertebrados y más de 4.000 especies de plantas. Esta riqueza conlleva un gran potencial para impulsar el crecimiento económico y la inclusión social, pero también implica una gran responsabilidad.

\section{EL SISTEMA DE ÁREAS PROTEGIDAS, COMO UNA ESTRATEGIA DE CONSERVACIÓN DEL ESTADO}

“Es el conjunto de áreas protegidas, actores sociales y estrategias e instrumentos de gestión que las articulan, para contribuir como un todo al cumplimiento de los objetivos de conservación del país. Incluye todas las áreas protegidas de gobernanza pública, privada o comunitaria, y del ámbito de gestión nacional, regional o local.” (Parques Nacionales, 2019) 


\section{LAS ÁREAS PROTEGIDAS, SEGÚN LA LEY 9.985 DE 2000, DEL EX PRESIDENTE LULA DA SILVA}

Para el año 2007, el gobierno del expresidente Lula Da Silva, presente un informe nacional sobre el estado de las áreas protegidas, a partir de este describiremos, el sistema en su totalidad, posteriormente analizaremos la participación social en la conservación, presentada en los documentos públicos de la expresidenta Dilma Rousseff, y finalmente analizaremos las últimas declaraciones del actual presidente Jair Bolsonaro, realizando un análisis del discurso presidencial, que se contrastará con los actuales hechos de deforestación del Amazonas Brasilero.

\section{CREACIÓN DEL SISTEMA NACIONAL DE UNIDADES DE CONSERVACIÓN EN BRASIL}

Según el Ministerio del Ambiente de Brasil: El marco político relacionado a la creación y administración de unidades de conservación en el Brasil está asentado en la Ley No. 9.985, que en julio de 2000 instituyó el SNUC; en el PNAP y, en el ámbito de la administración federal, en la creación del Instituto Chico Mendes para la Conservación de la Biodiversidad. A continuación describimos la articulación entre esos tres componentes de la actual política nacional para las áreas protegidas.

\section{EL SISTEMA NACIONAL DE UNIDADES DE CONSERVACIÓN DE LA NATURALEZA (SNUC)}

La preparación de un sistema de unidades de conservación en el Brasil tuvo inicio en 1976, en un trabajo denominado "Un análisis de prioridades en conservación de la naturaleza en la Amazonia", que fundamentó la elaboración del Plan del Sistema Nacional de Unidades de Conservación del Brasil, publicado entre 1979 y 1982 (MERCADANTE 2001). Concebido como un apéndice del II Plan Nacional de Desarrollo -que incrementa programas oficiales de colonización, infraestructura vial y energética y de explotación de los recursos naturales en la Amazonia brasileña- este documento propugna la inmediata creación de Parques Nacionales, Reservas Biológicas y Bosques Nacionales en la región, invariablemente en áreas descartadas por los proyectos económicos planificados. De hecho, entre 1979 y 1985, fueron creados diez Parques 
Nacionales, cuatro de los cuales están en la Amazonia; 13 son Reservas Biológicas, cinco de ellas en la misma región; y, 15 Estaciones Ecológicas, 11 en la Amazonia, totalizando 20 unidades de conservación de protección integral en esa parte del país, o 9,7 millones de hectáreas (BARRETO FILHO, 2003).

En ese mismo contexto histórico, las poblaciones amazónicas iniciaron una movilización contra la implementación de proyectos de desarrollo que traían daños a su estilo de vida, teniendo al frente líderes como el sindicalista Chico Mendes. Tal reacción llevó a la interrupción de financiamientos externos para estos proyectos y a la creación de una innovadora categoría de área protegida adaptada a las condiciones amazónicas, que conciliaba el uso económico, la regularización agraria y la conservación de los atributos naturales: la Reserva Extractiva, reglamentada en 1990 por el Decreto No. 98.897 como un "espacio territorial destinado a la utilización sostenible y la conservación de los recursos naturales renovables". La aparición de las poblaciones en el debate sobre el modelo de desarrollo para la región -del cual la creación de unidades de conservación era un componente- dio la oportunidad a la gradual incorporación de una visión más abarcadora de conservación en el ámbito del debate público, nacional e internacional, influenciando, posteriormente, a las normas y a las políticas públicas para el sector.

En 1988, año de la promulgación de la Constitución actualmente en vigor, el gobierno federal encomendó un análisis de las categorías de unidades de conservación existentes en el país, así como la elaboración de un anteproyecto de ley, con el objetivo de instituir un sistema nacional de unidades de conservación (MERCADANTE 2001). En mayo de 1992, una propuesta fue encaminada como Proyecto de Ley al Congreso Nacional por el entonces

Presidente de la República, permaneciendo en esa Casa hasta junio de 2000, cuando fue finalmente aprobada. El 19 de julio, fue publicado con vetos en el Diario Oficial de la Unión, como la Ley No. 9.985/2000, que instituyó el SNUC.

Sintéticamente, la Ley No. 9.985/2000 define 13 objetivos para el Sistema y lo organiza en torno de 12 categorías de manejo, divididas en dos grupos: el grupo de las unidades de conservación de protección integral, compuesto por cinco categorías; y, el grupo de las unidades de conservación de uso sostenible, con siete categorías. Los principales avances traídos por la nueva Ley a la estructuración de un sistema de unidades de conservación son:

- La planificación de la conservación debe asegurar representatividad a la diversidad de ecosistemas terrestres y marinos del país, protegiendo muestras significativas y ecológicamente viables del patrimonio biológico existente en el país; - El proceso de creación y la posterior administración de unidades de conservación deben ser realizados con la participación efectiva de 
las poblaciones locales, por medio de consultas públicas -exceptuando a las categorías: Reserva Biológica y Estación Ecológica- y de la creación de consejos de administración; - Poblaciones locales cuya subsistencia dependa de recursos naturales localizados dentro de las áreas declaradas como unidades de conservación deben ser justamente indemnizadas o proveídas con medios alternativos de subsistencia; - El Sistema debe buscar proteger grandes áreas integrando a las diferentes categorías y formas de manejo y uso del suelo, constituyendo corredores ecológicos cuando exista un conjunto de unidades de conservación de diferentes categorías, próximas, yuxtapuestas o sobrepuestas, la administración deberá ser efectuada de forma integrada y participativa, constituyendo mosaicos; - Inclusión en el SNUC de las Reservas Particulares de Patrimonio Natural (RPPN), fortaleciendo la integración de reservas en propiedades privadas a la estrategia de conservación en el país; Establecimiento de mecanismos de compensación para inversiones con significativo impacto ambiental, por medio de los cuales el inversionista esté obligado a destinar por lo menos el $0,5 \%$ del valor total de la inversión para la implementación y mantenimiento de unidades de conservación de protección integral; y Reconocimiento de la presencia humana en unidades de conservación de protección integral ya existentes, con sugerencias de mecanismos para enfrentarla, asegurando el respeto a los derechos de esas poblaciones. (Ministerio del medio ambiente de Brasil. 2007: 21 - 23)

\section{TIERRAS INDÍGENAS Y CONSERVACIÓN DE LA BIODIVERSIDAD EN EL BRASIL}

Con 109.231.453 hectáreas, las tierras indígenas ocupan aproximadamente el $12,8 \%$ de la superficie del territorio brasileño, del cual el 98\% está localizado en la Amazonia (ISA 2007). La distribución geográfica de las tierras bajo dominio indígena asegura la conservación de ecosistemas que ya no tienen más condiciones de ser protegidos en dimensiones adecuadas al mantenimiento de los procesos biológicos que generan y mantienen la biodiversidad. Específicamente en el llamado "arco de deforestación" -región de la Amazonia donde se encuentran los municipios que presentan las mayores tasas anuales de deforestación- las tierras indígenas funcionan como una barrera para la especulación agraria y para la conversión de la cobertura forestal en pastizales y cultivos agrícolas. Un estudio publicado en 2006 concluyó, basándose en el análisis de imágenes de satélite de diferentes categorías de unidades de conservación y tierras indígenas de la Amazonia brasileña, que estas últimas son especialmente importantes para prevenir la deforestación a larga escala en áreas del avance de la frontera agrícola (NEPSTAD et al. 2006). (Ibid, p. 24) 


\section{CUANDO LA CIENCIA Y LA POLÍTICA NO ENCUENTRAN EN UN LUGAR COMÚN (DESENCONTRO)}

A vida oblíqua? Bem sei que há um desencontro leve entre as coisas, elas quase se chocam, há desencontro entre os seres que se perdem uns aos outros entre palavras que quase não dizem mais nada. Mas quase nos entendemos nesse leve desencontro, nesse quase que é a única forma de suportar a vida em cheio, pois um encontro brusco face a face com ela nos assustaria, espaventaria os seus delicados fios de teia de aranha. Nós somos de soslaio para não comprometer o que pressentimos de infinitamente outro nessa vida de que te falo.

E eu vivo de lado - lugar onde a luz central não me cresta. E falo bem baixo para que os ouvidos sejam obrigados a ficar atentos e a me ouvir.

Clarisse Lispector. Agua Viva.

Para esta investigación se define "desencontro" como la falta de un lugar común para los investigadores y los políticos. Para la fecha, los científicos a través de fotografías satelitales y otros medios, tienen la seguridad de ofrecer datos concretos para la toma de decisiones políticas correctas; el sol ya no se puede tapar con un dedo, no existen hechizos, ni religiones; Sin embargo, la ignorancia impera y el conocimiento "científico" aun parece cosa de doctos!.

Que nos importa, la fotografía satelital que demuestra la deforestación, el pueblo ignora los datos, o cree que es un asunto de decisiones políticas, los políticos que ellos eligieron deben tomar sus decisiones, mientras el barco se hunde, o el clima cambia, o las especies desaparecen.

El siguiente relato demuestra como Brasil, naufraga en discusiones sobre sexualidad, armas, minorías, mientras los científicos demuestran pérdidas del bosque reales... Pero, un momento, ¿acaso el interés sobre el transexualismo y las minorías, y las armas, se relacionan con la política? Acaso, ¿girar de izquierda a derecha, o de derecha a izquierda, amenaza de alguna manera a nuestro barco denominado país?

Es posible que sí; para el tema que nos ocupa, las minorías y el medio ambiente tienen una relación intrínseca, por no decir absoluta. Si desaparece la selva, desaparecen las minorías étnicas que la habitan, ¿si exterminamos las minorías indígenas, quien protegerá la selva? Tal vez los políticos... Pero argumentativamente, todos los temas se mezclan generando confusión... Entonces vamos a los datos.

Global forest watch, ofrece datos, tecnología, y herramientas recientes, que empoderan a las personas en todas partes para proteger mejor los bosques. También permite crear sistemas de alertas tempranas para detectar deforestación en las 24 siguientes a la realización de la tala, ya 
que la Nasa, google, USGS, Hansen, se unieron para crear una base de datos global que nos permita conocer la realidad de las selvas.

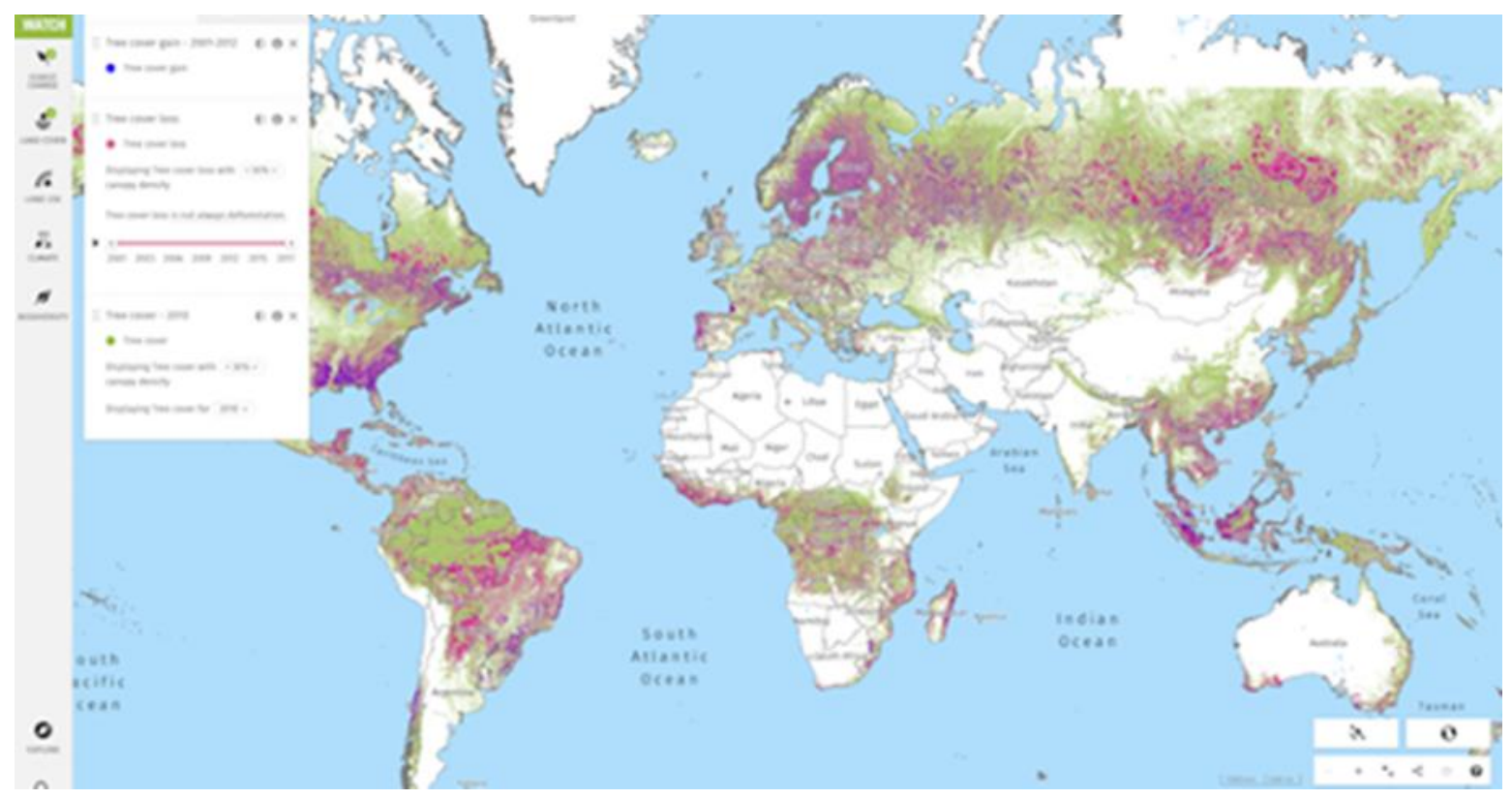

Mapa publicado en: https: //www.globalforestwatch.org/

\section{CAMBIO CLIMÁTICO}

Según Al Gore, premio nobel de la paz en 2007, por su lucha contra cambio climático: “la esencia de la crisis del calentamiento global está en el hecho de que importamos cantidades inmensas de energía de la costa terrestre y devolvemos entropía (o sea, desorden progresivo) a sistemas ecológicos hasta entonces estables, a pesar de dinámicos, y esenciales para la supervivencia de nuestra especie. Esos nuevos flujos de energía, originalmente importados del sol, hace varias eras, fueron estabilizados hace millones de años en forma de depósitos inertes de carbono.

Cuando empezamos a obtener estos depósitos y a lanzar los residuos de su combustión en la atmosfera, interrumpimos el patrón climático estable que existe desde el final de la última era glacial, hace diez milenios. Esto no sucedió, mucho antes del surgimiento de los primeros poblados y del inicio de la población agrícola. (AL GORE. 2013: p. 17)

Aunque existe un convenio para la lucha contra el cambio climático, (1992) y protocolos como Kyoto, (1997), el acuerdo de Paris, (2015) que intentan controlar las emisiones de gases efecto invernadero, a la fecha, esta lucha es ignorada, ataca por Donald Trump, quien el 1 de 
junio de 2017, anuncio el retiro de EEUU, de este acuerdo, así como la falta compromiso real de países como EEUU, China, India, entre otros grandes emisores de gases.

El discurso público proferido por el presidente de los Estados Unidos, ha hecho eco político en los discursos presidenciales de algunos mandatarios que, como Bolsonaro, desmienten a los científicos que han estudiado el cambio climático, e incluso, aparentan rechazar las donaciones internacionales, de recursos para la lucha contra el cambio climático como un discurso global, argumentando que esta es una forma de dominio, ya que según estos gobernantes, el discurso del patrimonio común de la humanidad, va en contra de la soberanía de los países, como lo veremos a continuación.

\section{AMAZONIA Y CAMBIO CLIMÁTICO}

Durante el año 2017, Analiz Vergara, experta sobre el Amazonas, y asesora de la organización internacional World Wild Found WWF, para la Amazonia, escribe: "A inicios de abril de este año la tragedia de la castaña en el norte de Bolivia ocupó varios titulares locales: 30 mil familias se quedarían sin su sustento durante seis meses debido a que la recolección de la nuez amazónica decayó en un $80 \%$ por un cambio en las condiciones climáticas. También hace algo más de un mes barrios enteros en Mocoa, ciudad amazónica colombiana, desaparecieron llevándose consigo más de 300 vidas humanas debido a la crecida de tres ríos. Estos eventos tienen causas múltiples, entre ellas variaciones naturales, pobreza y débil planificación. Sin embargo sabemos que el cambio climático puede interactuar con la vulnerabilidad del tejido socio-ambiental para amplificar calamidades como estas. Entonces, ¿qué nos depara el futuro?

Las predicciones indican que hasta finales del siglo XXI los cambios se van a acentuar -con hasta $3^{\circ} \mathrm{C}$ de aumento en temperatura en la Amazonía-, y con ellos se vería modificado el ciclo que regula el clima de Sudamérica, producto de la relación entre árboles y ríos amazónicos, corrientes del Atlántico, montañas de los Andes y circulación del viento. Las posibles consecuencias van desde pérdida de hábitat de especies clave, variación en las lluvias - de toda la región-, incremento de incendios forestales, sequías e inundaciones en el mejor de los casos, hasta una transformación definitiva de la vegetación en los escenarios más pesimistas. No sabemos en qué punto los cambios llegarían a ser más fuertes de lo que la Amazonía puede soportar, ni cuánto tiempo le tomaría recuperarse.

Finalmente, la respuesta a si la Amazonia sobrevivirá, aunque llena de incertidumbres, apunta a que la Amazonía cambiará con el cambio climático pero perdurará, siempre y cuando esté bien conservada. (la negrilla es nuestra) De ser así, hay una posibilidad, quizá pequeña, de 
que se adapte a las nuevas condiciones a lo largo del tiempo sin perder su esencia. Tal vez una pregunta más relevante es: ¿los seres humanos que dependemos de la Amazonía tal como la conocemos hoy en día, correremos la misma suerte? Algo que podemos afirmar con certeza es que el destino de la Amazonía y el nuestro se definirán por el éxito que tengamos en frenar las múltiples amenazas que afectan a este sitio tan importante para el planeta. (*) Analiz Vergara, Unidad de Coordinación Amazónica, WWF LAC.

\section{LA SELVA AMAZONICA, EL PULMÓN DEL MUNDO}

La selva tiene una gran cantidad de carbón o en sus miles de millones de árboles, que vienen siendo acumulados durante cientos o incluso miles de años.

Cada año, las hojas también absorben una gran cantidad de dióxido de carbono que, de lo contrario, se quedaría en la atmósfera, lo que incrementaría el aumento de las temperaturas globales.

Según una investigación publicada por la Universidad de Leeds (Reino Unido) en 2017, los árboles de la selva amazónica extrajeron dióxido de carbono equivalente a las emisiones de combustibles fósiles de la mayoría de los nueve países que poseen o bordean el bosque entre 19802010. (BBC.2019)

En 2018 Brasil, hogar de la mayor parte del Amazonas, encabezó la lista del país que más bosques tropicales primarios o nativos perdió.

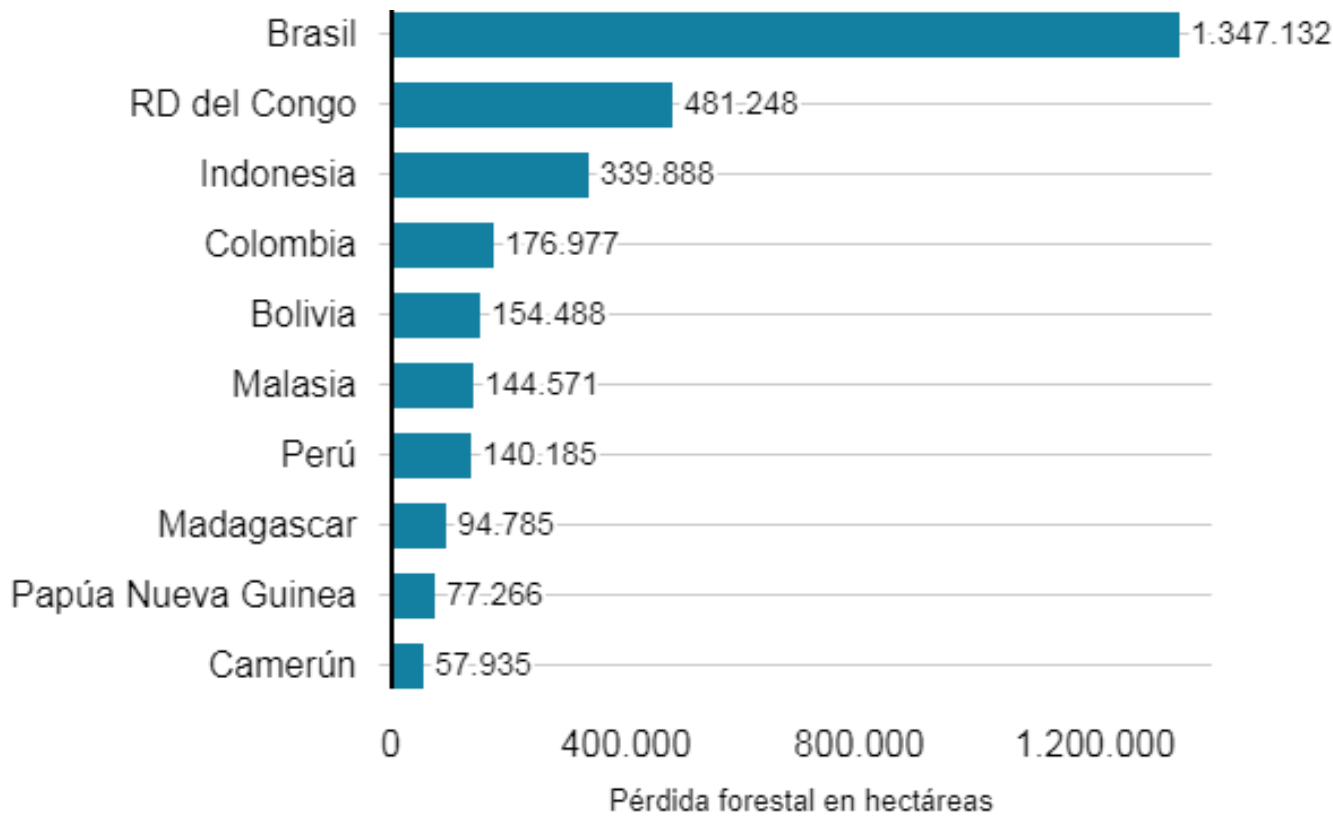

Fuente: instituto de recursos mundiales, citado en BBC, 2019 


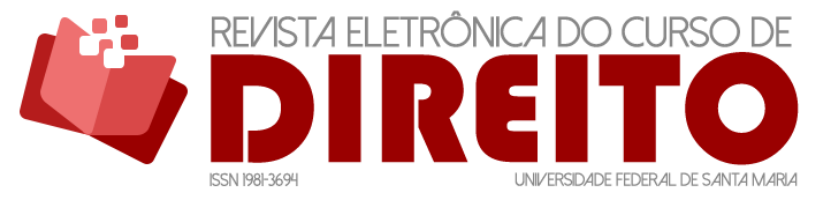

DESPROTEGER LO PROTEGIDO, ESTRATAGEMAS PARA SUSTRAER Y/O PERMITIR EL DECRECIMIENTO DE LAS AREAS PROTEGIDAS, ESTUDIO DE CASO EN EL AMAZONAS BRASILERO

En concreto en ese año se registró la desaparición de más de 1,3 millones de hectáreas, reveló en abril el informe de Global Forest Watch, del Instituto de Recursos Mundiales. (Ibid, BBC. 2019) Según los satélites de la NASA, los incendios crecieron un $38 \%$ este año, y siete de las ciudades con los incendios más dramáticos están en la lista de los más deforestados.

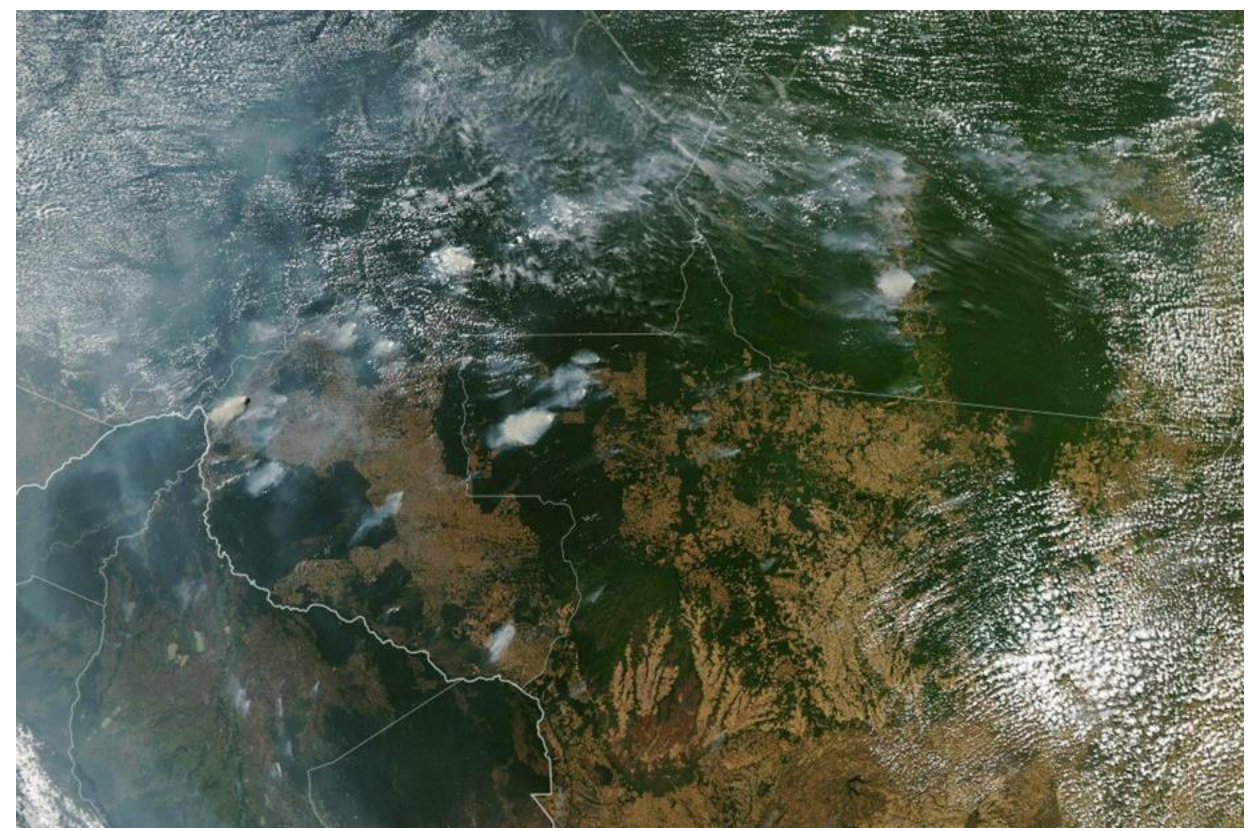

Esta imagen del Observatorio de la Tierra de la NASA obtenida el 21 de agosto de 2019, capturada por el espectroradiómetro de imágenes de resolución moderada (MODIS) en el satélite Aqua de la NASA, muestra varios incendios en los estados brasileños de Amazonas. AFP

A principios de agosto, el Gobierno del presidente brasileño, Jair Bolsonaro, destituyó a Ricardo Osorio Galvao, director del estatal Instituto Nacional de Investigaciones Espaciales (INPE, por su sigla en portugués), órgano responsable por monitorear y divulgar los datos sobre deforestación en el país suramericano. Las cifras que divulgó antes de salir del INPE son preocupantes: La parte brasileña de la Amazonía ha perdido más de 3000 kilómetros cuadrados de área boscosa desde que Bolsonaro asumió el cargo en enero, un aumento de 39\% respecto al mismo periodo del año pasado, de acuerdo con la agencia del gobierno que monitorea la deforestación.

Tan solo en junio, cuando empezó la temporada más seca, lo que facilita la tala, la tasa de deforestación aumentó de manera drástica: alrededor de $80 \%$ más pérdidas que en junio de 2018.

A pesar de las críticas de la administración Jair Bolsonaro, los datos de la deforestación del Instituto Nacional de Investigación Espacial (INPE) no son los únicos que muestran el progreso de la tala en la Amazonia. Los satélites de la NASA han visto un aumento del $65 \%$ en los incendios 
en Brasil desde principios de 2019 en comparación con el mismo período en 2018. Este aumento se produce principalmente en el norte y el medio oeste de la selva de ese país.

Ahora, existe una relación directa entre el aumento de la quema y el crecimiento de la deforestación. De los 10 municipios que registraron los incendios más extensos en 2019, siete están en la lista de municipios con el mayor número de advertencias de deforestación. Los otros tres municipios de la lista pertenecen al bioma Cerrado, el segundo ecosistema más grande de ese país, compuesto en su mayoría por sabanas. (El Espectador. 2019)

\section{LA AMAZONIA ES NUESTRA, NO SUYA!}

La Amazonia es nuestra no suya, fue la respuesta del actual presidente brasilero a un periodista europeo. Ironizado sobre sí mismo, Bolsonaro se autodenomina “capitán motosierra” dice "que culpen a los indios o a los marcianos", de la destrucción de la Amazonia, concomitante con este discurso público, apoya a la bancada ruralista, que necesita tierras para su aprovechamiento, dice que no dará un centímetro de tierra a los indígenas durante su gobierno, y como plan de gobierno apoya las hidroeléctricas en el Amazonas.

“Durante su campaña para la presidencia en 2018, Bolsonaro declaró que las amplias tierras protegidas de Brasil eran un obstáculo al crecimiento económico y prometió abrirlas a la explotación, para fines comerciales. A siete meses de su mandato, eso ya está sucediendo.

La parte brasileña de la Amazonía ha perdido más de 3000 kilómetros cuadrados de área boscosa desde que Bolsonaro asumió el cargo en enero, un aumento de 39 por ciento respecto al mismo periodo del año pasado, de acuerdo con la agencia del gobierno que monitorea la deforestación.

Tan solo en junio, cuando empezó la temporada más seca y templada que facilita la tala, la tasa de deforestación aumentó de manera drástica: alrededor de 80 por ciento más pérdidas que en junio de 2018.

Estos aumentos se registran en momentos en que el gobierno de Bolsonaro ha retirado medidas medioambientales como las multas, advertencias y la confiscación o destrucción de equipo ilegal que haya en áreas protegidas". (New York Times. 2019)

El 5 de junio, dia mundial del medio ambiente, Jair Bolsonaro afirmo que la primera misión de su gobierno es “não atrapalhar quem quer produzir”. (GLOBO. 2019) 
Bolsonaro llegó al poder con una agenda populista respaldada por empresas agrícolas y pequeños agricultores, muchos de los cuales creen que es muy grande el área protegida de la región del Amazonas y que el personal de medioambiente tiene demasiada influencia.

En cuanto a los indígenas, el actual presidente afirmo durante su campaña "Se eu assumir, índio não terá mais $1 \mathrm{~cm}$ de terra" (esquerda diario. 2018)

De igual manera, el plan de gobierno actual retoma, la apertura de hidroeléctricas que estuvieron cerradas durante años, por los pésimos efectos que tendrían sobre los territorios indígenas y el medio ambiente

Por su parte, el principal asesor de seguridad del presidente, el general Augusto Heleno

Pereira, le dijo a la agencia Bloomberg el mes pasado que era una tontería que el Amazonas fuera parte del patrimonio mundial.

La Amazonía es brasileña, la herencia de Brasil y debe ser tratada por Brasil en beneficio de Brasil, dijo. (op cit, New York Times. 2019)

Lo cual es cierto, conforme con el artículo 225 de la constitución política de Brasil de 1988:

40. La floresta Amazónica brasileña, la Mata Atlántica, la Sierra del Mar, el Pantanal Mato Grossense y la zona Costera son patrimonio nacional, y su utilización se hará en la forma de la ley, dentro de las condiciones que aseguren la preservación del medio ambiente, incluyendo lo re referente al uso de los recursos naturales.

\section{ENMIENDAS CONSTITUCIONALES, QUE AFECTAN LA PARTICIPACIÓN SOCIAL EN LA CONSERVACIÓN DEL AMAZONAS BRASILERO}

Existe una enmienda constitucional para detener la creación de nuevas áreas protegidas:

El 20 de marzo de 2018, el Gobierno estatal había dictado un decreto mediante el cual se creaban 11 áreas protegidas. Sin embargo, al escuchar los rumores acerca de la inminente firma de este decreto, el diputado estatal de derecha Alex Redano reaccionó rápidamente. Así, introdujo una enmienda constitucional (PEC 037/2017) que impedía la creación de todo tipo de área protegida por parte del Gobierno estatal sin la consulta previa a la Asamblea. Esta enmienda fue aprobada el mismo día en que se promulgó el decreto que creaba las 11 áreas protegidas.

Al realizar esta enmienda constitucional, promovida por la "bancada ruralista", es decir el mismo grupo político que apoya a Jair Bolsonaro, la Asamblea legislativa de Rodonia, decidió El 25 de septiembre, y tras menos de una hora de debate, los diputados estatales de la Asamblea 
Legislativa de Rondonia eliminaron 11 áreas protegidas que abarcan cerca de 600000 hectáreas de bosque. Esta cifra equivale al $3 \%$ de la superficie total de ese estado. La medida fue aprobada en tiempo récord: el proyecto de ley ingresó a la Asamblea en la mañana y para la tarde ya se había convertido en ley.

En el año 2017, La organización ecologista WWF advirtió, sobre las desventajas del Sistema Nacional de Unidades de Conservación (SNUC) en Brasil, lugares que pueden convertirse en Áreas de Protección Ambiental (APAs), un estatus menos rígido y que facilitaría la deforestación.

\section{EL GASTO PÚBLICO SOCIAL}

En diciembre de 2016, el Senado de Brasil, aprobó una enmienda constitucional, que congeló el gasto público social durante 20 años. Este proyecto fue presentado por el presidente Michel Temer, y por su carácter de enmienda, debió ser votado dos veces en la cámara Alta del Senado de la república.

La enmienda constitucional dice que "el aumento del gasto público anual estará limitado durante los próximos veinte años a la tasa de inflación del ejercicio anterior y que este techo, solo podrá ser revisado, una vez transcurrida la primera década".

Según el Gobierno este límite detendrá, el aumento de la deuda pública, en relación al Producto Interno Bruto (PIB) lo que considera "indispensable" para recuperar el equilibrio fiscal”. (EL PAIS. 2016) esta decisión, afectará irremediablemente, la salud, la educación y por supuesto la "participación social en la conservación de las áreas protegidas”

\section{CONCLUSIÓN}

Nos encontramos en un momento histórico en el que la ciencia tiene todo para aportar a la política, especialmente frente a los datos sobre el cambio climático y la perdida de la diversidad biológica; además, existen los convenios internacionales para enfrentar los cambios antropogénicos que afectan a la tierra y nuestra supervivencia como especie en los siglos venideros; sin embargo, para el estudio de caso en la Amazonia brasilera, no existe voluntad política alguna para afrontar estos problemas ambientales; por el contrario, el discurso político del actual presidente es de burla, frente a los actores que defienden la selva, bien sea los indios, los periodistas, o los ambientalistas. Este discurso político y las enmiendas constitucionales que congelan el gasto público social, y someten las decisiones de crear nuevas áreas protegidas de 
carácter estatal, a instancias políticas locales tales como las asambleas legislativas, han posibilitado que la selva amazónica, patrimonio común de la humanidad, pulmón del mundo, arda.

\section{RECOMENDACIONES:}

Continuar con la estrategia ARPA, para la protección de la amazonia.

Eliminar la figura de "licencias ambientales" porque contienen dentro de su concepción central el concepto de riesgo y daño, al considerar las áreas protegidas de carácter estatal como de conservación "perpetua" no debe existir ninguna posibilidad de daño o riesgo dentro de si, por lo tanto, NO SE DEBEN CONCEDER LICENCIAS AMBIENTALES DE NINGUN TIPO DENTRO DE LAS ÁREAS PROTEGIDAS DE CARÁCTER ESTATAL.

Por último y no por ello menos importante, se sugiere, crear grupos de apoyo internacional, que estén autorizados previamente a interferir, para los sofocar los incendios masivos que vienen siendo registrados actualmente en el Amazonas, considerado como el pulmón del mundo.

\section{REFERÊNCIAS}

AL GORE. (2013) el futuro. HSM Editora. Sao Paulo.

BOURDIEU, Pierre. Contra la política de despolitización: los objetivos del Movimiento Social Europeo. 2001. Disponible en: http://pt.scribd.com/doc/228623619/Bourdieu-Pierre-Contra-LaPolitica-de-Despolitizacion-Los-Objetivos-Del-Movimiento-Social-Europeo\#scribd. Consultado el 25 fev. 2015.

ABC. (2018) Critican inadecuado Sistema Nacional de Unidades de Conservación. Disponible en: https://www.abc.es/natural/biodiversidad/abci-critican-inadecuado-sistema-nacionalunidades-conservacion-brasil-201707181106_noticia.html.

BBC (2019) Amazonas: por qué se ha acelerado la deforestación con la llegada de a la presidencia de Brasil.

EL ESPECTADOR. (2019) Faleiros Gustavo. Infoamazonia. Satélites de la NASA muestran cómo arde la Amazonia de Brasil. Publicación digital en:

https://www.elespectador.com/noticias/medio-ambiente/satelites-de-la-nasa-muestran-comoarde-la-amazonia-de-brasil-articulo-876950

EL PAIS. (2016) El Senado brasileño aprueba el límite de gasto propuesto por Temer 53 votos frente a 16 apoyan el polémico proyecto de ley que impondrá recortes en los próximos veinte años Publicación digital en: https://elpais.com/internacional/2016/12/13/actualidad/1481646098_476701.html

ESTADAO. (2019) Bolsonaro retoma o plano de erguer grandes hidroelétricas na Amazonia Publicación digital en: https://economia.estadao.com.br/noticias/geral,bolsonaro-retoma- 
plano-de-erguer-grandes-hidreletricas-na-

amazonia, 70002977141?fbclid=IwAR2L8UdiOW4cwNVTZTmohvFDaWK-

SrY740XGve_2E1WINOPV81s96n5J47g

ESQUERDA DIARIO (2018) Bolsonaro: “Se eu assumir, índio não terá mais $1 \mathrm{~cm}$ de terra"

Publicacion digital en: http://www.esquerdadiario.com.br/Bolsonaro-Se-eu-assumir-indio-nao-

tera-mais-1cm-de-terra?fbclid=IwAR3_Dx8zuidd5mVgAyLx3cDaGpl5ScH2o0XEqV-

EUiOs2pZlV8148xRjsbk

ESCOBAR, Arturo. El final del salvaje, naturaleza, cultura y política en la antropología contemporánea. Bogotá: Instituto Colombiano de Antropología ICAN y Centro de estudios de la realidad Colombiana CEREC, 1999.

GLOBAL FOREST WATCH (2019) Monitoreo de bosques diseñado para la acción. Publicación digital en: https://www.globalforestwatch.org

GLOBO. (2019) En el dia mundial del medio ambiente, Jair Bolsonaro afirmo que la primera misión de su gobierno es "não atrapalhar quem quer produzir Publicación digital en:

https://oglobo.globo.com/sociedade/no-dia-mundial-do-meio-ambiente-

ILSA; Diversidad biológica y cultural. Retos y propuestas desde America Latina. S.L. Margarita Flores. Ed: 1999.

LISPECTOR CLARICE. Agua viva. Biblioteca Clarice Lispector. Publicación digital en: http://www.siruela.com/archivos/fragmentos/Agua_viva.pdf

MINISTERIO DEL MEDIO AMBIENTE DE BRASIL. (2007) Informe Nacional sobre áreas protegidas de Brasil. Publicación digital en:

https://www.mma.gov.br/estruturas/sbf2008_dap/_publicacao/149_publicacao16122010111031 . $\mathrm{pdf}$

NEW YORK TIMES. (2019) La destrucción amazónica se acelera durante el gobierno de Bolsonaro Publicación digital en:_https://www.nytimes.com/es/2019/07/29/deforestacion-amazonasbolsonaro/

Organización de las Naciones Unidas. La biodiversidad de Brasil, recibe apoyo en linea. Publicacion digital en: https://www.unenvironment.org/es/noticias-y-reportajes/reportajes/labiodiversidad-de-brasil-recibe-apoyo-en-linea

PARQUES NACIONALES NATURALES. (2019) Publicacion digital en: http://www.parquesnacionales.gov.co/portal/es/sistema-nacional-de-areas-protegidas-sinap/

VERGARA ANALIZ. (2017) ¿Sobrevivirá la amazonia al cambio climático? WWF. Unidad de conservación amazónica. Publicación digital en:

https://www.efeverde.com/blog/amazonia/amazonia-cambio-climatico-\%20analiz-

vergara-\%20wwf/

Artigo convidado / Publicado em: 09.10.2019 
ISSN 1981-3694

(DOI): $10.5902 / 1981369440442$

DESPROTEGER LO PROTEGIDO, ESTRATAGEMAS PARA SUSTRAER Y/O PERMITIR EL DECRECIMIENTO DE LAS AREAS PROTEGIDAS, ESTUDIO DE CASO EN EL AMAZONAS BRASILERO

Diana Magally Correa Valero

\section{COMO FAZER REFERÊNCIA AO ARTIGO (ABNT/BRASIL):}

CORREA VALERO, Diana Magally. Desproteger lo protegido, estratagemas para sustraer y/o permitir el decrecimiento de las áreas protegidas, estudio de caso en el Amazonas Brasilero. Revista Eletrônica do Curso de Direito da UFSM, Santa Maria, RS, v. 14, n. 3, e40442, set./dez. 2019. ISSN 1981-3694. DOI: http://dx.doi.org/10.5902/1981369440442. Disponível em:

https://periodicos.ufsm.br/revistadireito/article/view/40442 Acesso em: dia mês. ano.

Direitos autorais 2019 Revista Eletrônica do Curso de Direito da UFSM

Editores responsáveis: Rafael Santos de Oliveira e Angela Araujo da Silveira Espindola

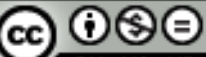

BY NC ND

Esta obra está licenciada com uma Licença Creative Commons Atribuição-NãoComercial-SemDerivações 4.0 Internacional.

\section{SOBRE A AUTORA}

Diana MAgally CoRRea Valero

Doctora en ciencias jurídicas, UNIVALI, Brasil; Doctora en derecho, Universidad de Alicante. Magister en Antropología, Universidad Nacional de Colombia; Abogada, Universidad de Caldas. Consultora de las Naciones Unidas, docente e investigadora de la Universidad de Caldas, Colômbia. 